\author{
JUAN ESTRUCH \\ ANTONIO M. GUUELL *
}

\title{
LA ELECCION DE CARRERA Y SUS MOTIVACIONES
}

I.jias para un estudio sobre el tema, a partir de los datos de una encuesta entre estudiantes de COU de Barcelona.

\section{INTRODUCCION}

Corno complemento a una investigación en curso sobre la profesión de Asistente Social, y con el fin de poder comparar las motivaciones dadas para cursar dichos estudios con las de otras carreras, se procedió durante el primer trimestre del año académico $1974-75$ a efectuar un breve sondeo entre alumnos de distintos COU de Barcelona.

El interés intrínseco de las informaciones obtenidas a partir de este sondeo nos ha inducido a la realización de un análisis secundario de los datos, cuyos principales resultados se ofrecen a continuación.

El cuestionario elaborado para proceder a la encuesta constaba de las tres preguntas siguientes:

1) ¿Qué estudios piensa cursar después del COU?

2) ¿Cuáles son los motivos que le han inducido a elegir esta carrera?

3 ¿Cuâl es a su modo de ver el papel que en la sociedad española actual debiera desempeñar el miembro de la profesión que ha elegido?

* Con la colaboración de Imma AYZA y Carmen BRILIAS. 
Como datos de identificación se pedían, por otra parte, los siguientes: lugar y año de nacimiento, sexo, y profesión del padre.

Deliberadamente breve y simple, el cuestionatio fue cumplimentado por los alumnos del Curso de Orientación Universitaria en la propia clase.'

En este artículo examinaremos los tesultados obtenidos, pattiendo de una descripción de la población estudiada, para analizar luego cuáles son las carteras elegidas y los motivos aducidos.

\section{Delimitación Dę unIVerso}

Previa eliminación de los cuestionatios no válidos o deficientemente cumplimentados, pasaron a exploración los resultados correspondientes a un total de 930 respuestas, distribuidas por escuelas y sexn según aparece en la TABLA 1.

TABLA 1

Delimitación del Universo

\begin{tabular}{|c|c|c|c|}
\hline & CHICAS & CHICOS & TOTAL \\
\hline COU J. Bofill & $\begin{array}{l}108 \\
35,8 \\
\end{array}$ & $\begin{array}{l}194 \\
64,2 \\
\end{array}$ & $\begin{array}{l}302 \\
100,0 \\
\end{array}$ \\
\hline COU Boscán & $\begin{array}{l}146 \\
100,0 \\
\end{array}$ & $\underline{0,0}$ & $\begin{array}{l}146 \\
100,0 \\
\end{array}$ \\
\hline COU Jesuitas, Caspe & $\begin{array}{r}27 \\
23,5 \\
\end{array}$ & $\begin{array}{l}88 \\
76,5 \\
\end{array}$ & $\begin{array}{l}115 \\
100,0 \\
\end{array}$ \\
\hline COU Iesuitas Caspe (nocturno) & $\begin{array}{l}6 \\
6,6 \\
\end{array}$ & $\begin{array}{r}85 \\
93,4 \\
\end{array}$ & $\begin{array}{r}91 \\
100,0 \\
\end{array}$ \\
\hline Cov Jesuitas, Sartiá & $\begin{array}{r}55 \\
100,0 \\
\end{array}$ & $-0,0$ & $\begin{array}{l}55 \\
100,0\end{array}$ \\
\hline COU Sagrado Corazón, Sarriá & $\begin{array}{l}101 \\
45,7 \\
\end{array}$ & $\begin{array}{r}120 \\
54,3 \\
\end{array}$ & $\begin{array}{l}221 \\
100,0\end{array}$ \\
\hline TOTAL & $\begin{array}{r}443 \\
47,6 \\
\end{array}$ & $\begin{array}{r}487 \\
52,4 \\
\end{array}$ & $\begin{array}{l}930 \\
100,0 \\
\end{array}$ \\
\hline
\end{tabular}

1. De nuevo debemos hacet constar aquí nuestra gratitud a los estudiantes, a los directores de los COU élegidos y al profesorado, por su desinteresada colaboración. 
Esta TABLA 1 exige un par de observaciones:

a) Cumplimentaton la encuesta los alumnos de la totalidad de los grupos de los COU Jaume Bofill, Sagrado Corazón de Sarriá, y nocturnos del Colegio de Jesuitas de la calle Caspe; la totalidad menos uno de los grupos del Instituto Femenino de Enseñanza Media Boscán y de los Jesuitas de Caspe (régimen diurno), y 55 chicas del Colegio de Jesuitas de Sarriá, elegidas con el fin de obtener unos totales semejantes de chicos y chicas.

b) Esta relativa similitud de ambas categorias $(47.6 \%$ de chicas, $52.4 \%$ de chicos) no es, desde luego, representativa del conjunto de la población barcelonesa que cursa los estudios de COU. ${ }^{2}$ La infratrespresentación del sector masculino en nuestro univetso respondía al deseo, no sólo de trabajar sobre grupos de dimensiones semejantes, sino sobre todo de obtener un número proporcionalmente más elevado de respuestas femeninas, dado el objetivo primordial del estudio de posibilitar una serie de comparaciones con los Asistentes Sociales, los cuales constituyen, como es sabido, un ejemplo paradigmático de monopolio femenino del ejercicio de una profesión. ${ }^{3}$

\section{El estudiante de COU en Barcelona:}

\section{«UN BARCELONES, DE 17 AÑOS, DE CLASE MEDIA PARA ARRIBA»}

\section{1. «Un barcelonés».}

Más de las tres cuartas partes de los estudiantes de COU interrogados nacieron en la misma Barcelona (chicas, $78.3 \%$; chicos, $79.5 \%$ ), y el $90 \%$ del conjunto son originarios de Cataluna (TABLA 2). Tampoco aquí los porcentajes son representativos de la población barcelonesa o catalana global,

2. En el curso 1971-72 la distribución de los alumnos de COU era en Barcelona de $79,2 \%$ de chicos y $20,8 \%$ de chicas. Cf. el volumen Estadistica Municipal. Resumen del año 1972, publicado por el Ayuntamiento de Barcelona, 1974, p. 178.

3. Bien ilustrativo es el hecho de que entre las 1273 personas que en total han cursado los estudios de Asistente Social en Cataluña, figuran tan sólo 5 hombres frente a 1268 mujeres. Cf. A. GUELL y J. ESTRUCH, «Elements sociográfics per a l'análisi d'una professió: els Assistents Socials a Catalunyan, Revista de Treball Social, en prensa. 


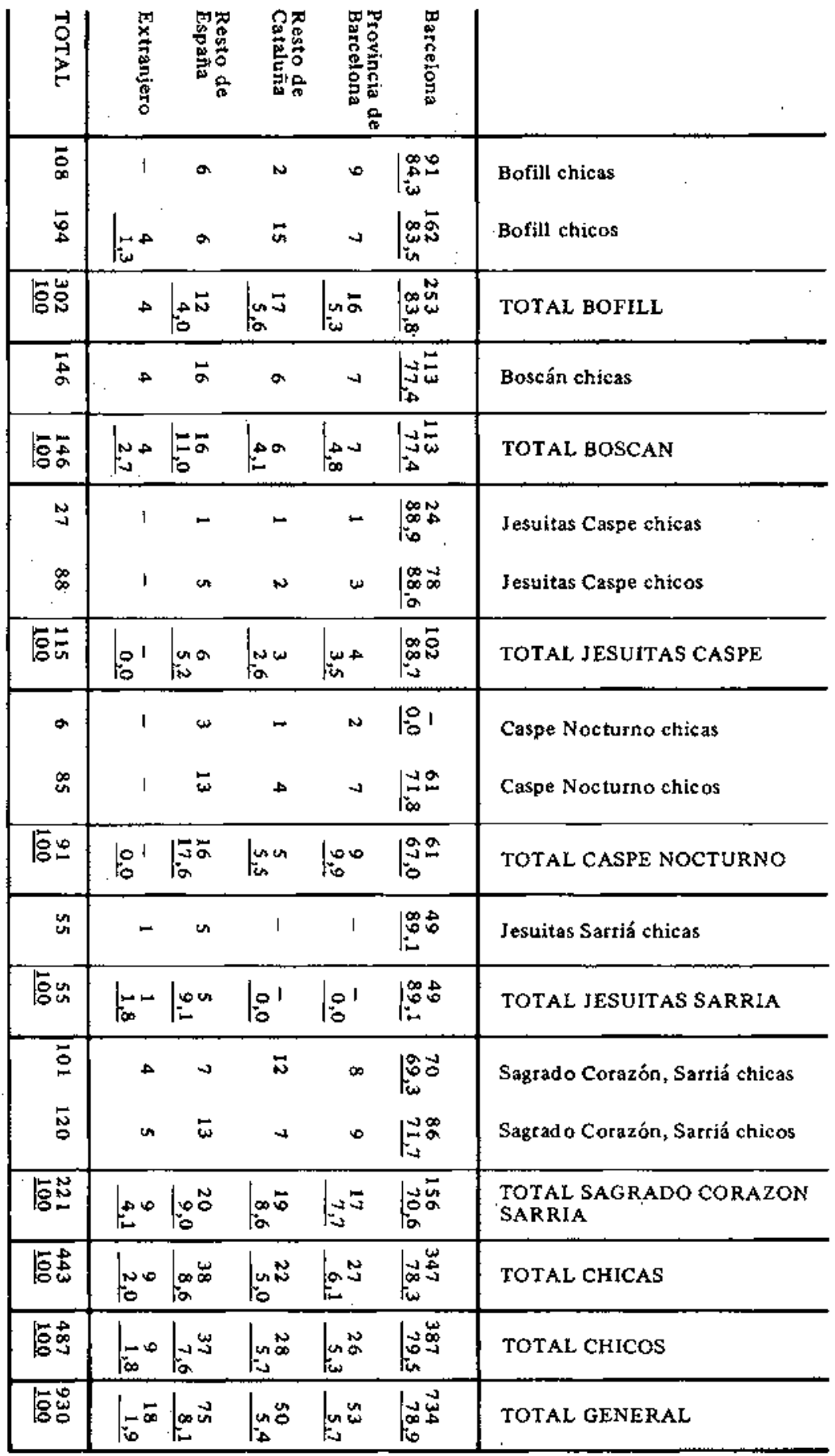


pero en esta ocasión no son el estudio o la forma de elaborar la muestra los culpables de la desproporción...

Como era lógicamente previsible, el Instituto Nacional (Boscán) y el curso nocturno (Jesuitas de Caspe) son los dos centros que arrojan un porcentaje más elevado de estudiantes no catalanes $(11 \%$ y $17.6 \%$ respectivamente), mientras que los catalanes son proporcionalmente más numerosos en el Bofill y en los Jesuitas de Caspe (diurno), con un $95 \%$ del total en ambos casos. Es asimismo en este último centro, así como en el de Sartiá igualmente dirigido por los jesuitas, donde los barceloneses constituyen una aplastante mayoría (casi el $90 \%$ ).

La distribución entre chicos y chicas no ofrece en este caso apenas diferencias.

\section{2. «De 17 años».}

De edad comprendida entre los 16 y los 18 años, habríamos de decir con mayor exactitud. En efecto, la suma de los nacidos en 1957 y 1958 es del orden del $83.8 \%$ (chicas, $86.7 \%$; chicos $81.1 \%$ ). Si entre chicos y chicas las diferencias son poco acusadas (TABLA 3), aunque con una leve tendencia hacia una mayor juventud en los muchachos que en las muchachas, la distribución por escuelas arroja, por el contrario, diferencias sumamente significativas. Y son de nuevo el curso nocturno de Caspe y el Instituto Boscán los que destacan del resto de los centros por la mayor edad de sus alumnos. Así, si el conjunto de los nacidos en 1957 y 1958 representaba según dijimos el $83.8 \%$ del total, el porcentaje oscila entre el 90 y el $95 \%$ en los COU Bofill, Caspe (diurno) y Jesuitas de Sarriá, alcanza un valor próximo a la media en el Boscán, y rebasa apenas el $25 \%$ en el Caspe nocturno. Los nacidos antes de 1956 constituyen, en cambio, el $50 \%$ de los alumnos de este COU nocturno, el $7 \%$ de las muchachas del Instituto Boscán, el $3 \%$ de los estudiantes del Sagrado Corazón, y no existen en los tres colegios restantes (con una sola excepción).

Dicho de otra forma, en el momento de la realización de la encuesta (noviembre-diciembre 1974) la edad media de los estudiantes de COU era de 16 años y medio en los centros Jaume Bofill, Caspe (diurno) y Sarriá (Jesuitas), se situaba entre los 26 y medio y los 17 en el Sagrado Corazón, rebasaba ligeramente los 17 en el Boscán, y se aproximaba a los 19 en el curso nocturno de los Jesuitas de Caspe. 


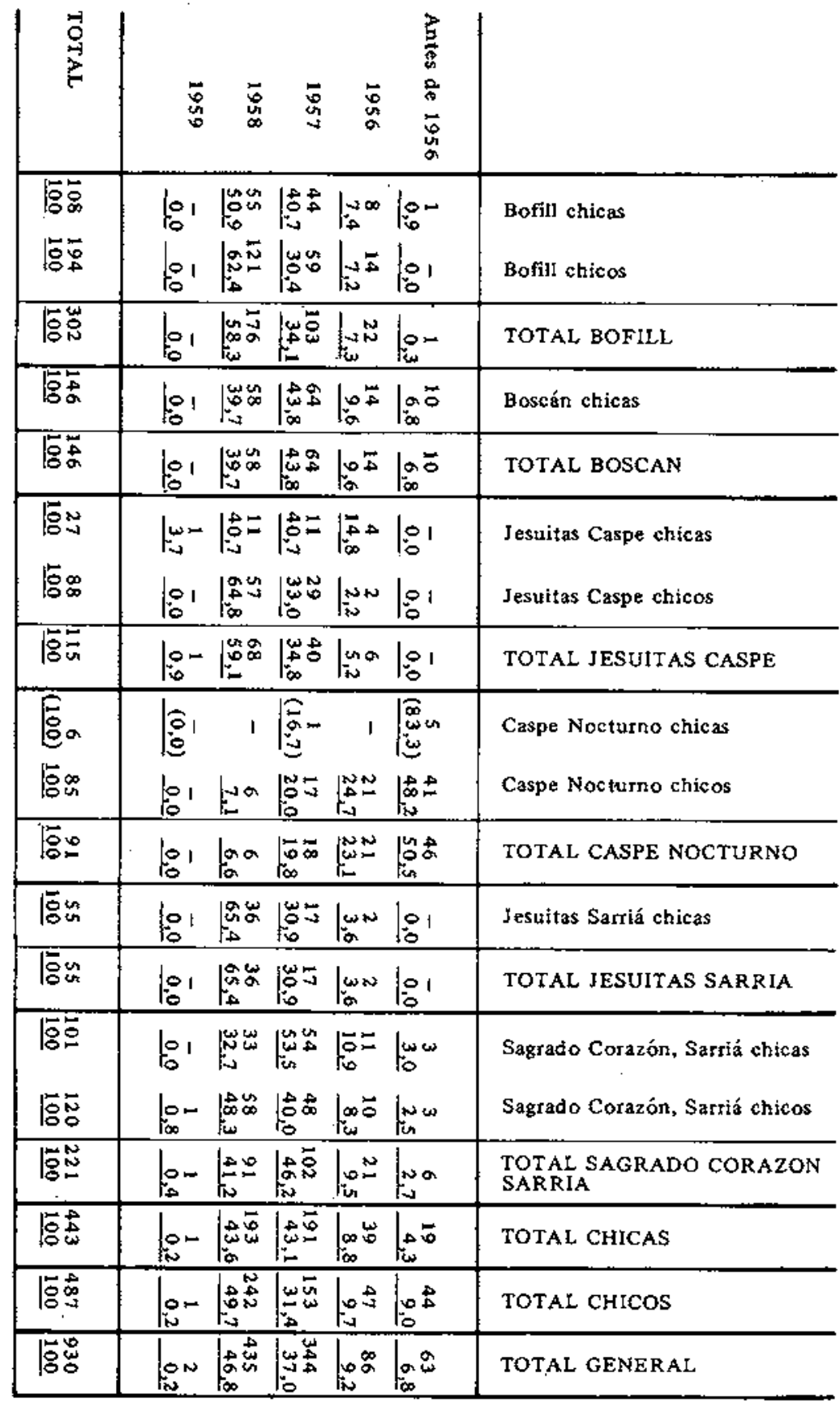




\section{3. «De clase media para arriba».}

Para la subdivisión de la población en categotias socio-profesionaies se han establecido las seis categorías siguientes: Obreros, empleados, comercio (comerciantes, artesanos, independientes), carreras de grado medio (peritaje, aparejador, magisterio, etc.), profesiones liberales de grado superior (médicos, abogados, arquitectos, etc.) e industriales (dueños o directores de em. presas e industrias, altos cargos ejecutivos, etc.).

En la TABLA 4 se presentan los resultados correspondientes a esta variable, distribuidos por sexos y por escuelas.

Un análisis de las columnas correspondientes a los totales de chicas $y$ chicos permite verificar algo, no por sabido menos interesante de comprobar; a saber, el hecho de que aún en la actualidad los hijos de las categorías socio-ptofesionales más bajas abundan más entre el alumnado masculino, mientras que las muchachas son proporcionalmente más numerosas en los estratos sociales más elevados. Dado que no es presumible que la explicación del fenómeno radique en una realidad de tipo biológico (en cuyo caso los obreros tendrían mayor propensión a procrear hijos varones y los industriales, por ejemplo, a engendrar niñas), preciso es tecurrit a una interpretación sociológica del fenómeno: cuando los estudios - no gratuitos- de los hijos suponen un esfuerzo o un sacrificio de tipo económico, se tiende a consentir el esfuerzo en el caso de los chiccs en mayor medida que en el de las chicas, a cuyo curriculum académico se ha concedido tradicionalmente menor importancia; por el contrario, en aquellas categotías sociales en las que los estudios no suponen ningún obstáculo grave, se restablece el equilibrio y cursan estudios las muchachas igual que los muchachos. Vemos así, en efecto, cómo el porcentaje de estudiantes de COU hijos de obreros, empleados y titulados de grado medio es más elevado entre el alumno masculino, mientras que el femenino alcanza forcenrajes más elevados en las categorías de grado superior e industrial.

Por otra parte, la distribución a partir de los distintos centros de ensenanza estudiados arroja de nuevo resultados interesantes y diferencias significativas y concordantes con lo ya observado en los apartados anteriores. Asi, los hijos de profesiones liberales de grado superior constituyen aproximadamente un $30 \%$ del alumnado de los centros Bofill, Jesuitas de Caspe y Sarriá, y Sagrado Corazón, frente a un $13 \%$ tan sólo en el Insti. tuto Boscán, y a un rotundo cero en el COU nocturno de los Jesuitas. Er, el extremo opuesto, los hijos de los obreros están ausentes de los COU de los Jesuitas, oscilan en torno al $5 \%$ tan sólo en el Bofill y el Sagrado Corazón, representan cerca del $20 \%$ del estudiantado del Boscán, y casi la mitad del total de alumnos del COU nocturno de la calle Caspe. 


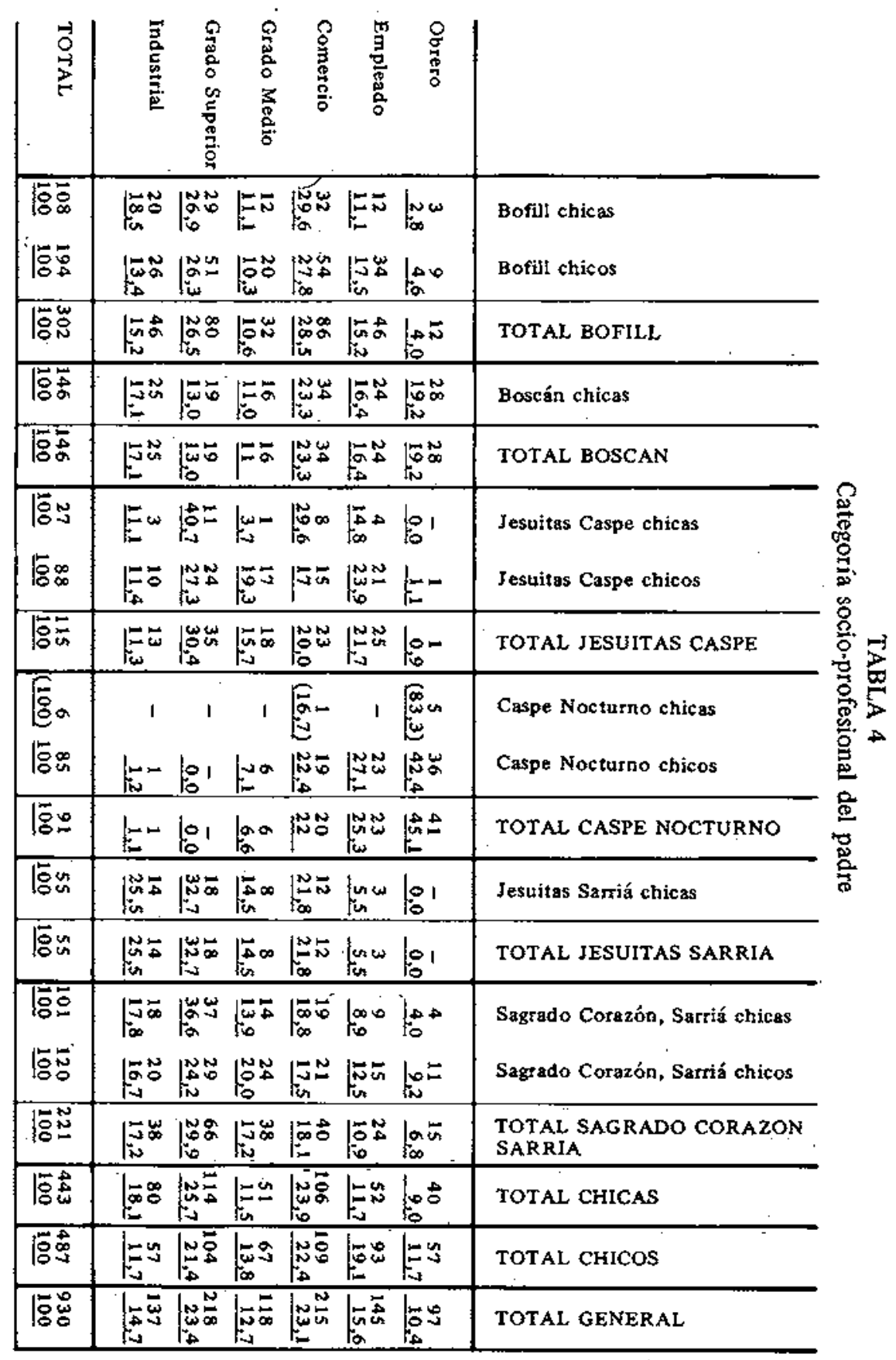


En definitiva, a la vista de los resuitados gtobales (véase la columna «Total general» de la TABLA 4), podría casi enunciarse una especie de postulado educativo que rezaría así: "La presencia de las categorías socioprofesionales en los últimos niveles de la enseñanza media ( $y$, por ende, en la Universidad) es inversamente proporcional a su peso numérico en la sociedad global». El hecho de que hallemos prácticamente el mismo número de hijos de industriales que de empleados, y mís del doble de miembros de profesiones liberales que de familias obreras, es un índice inequivoco de la distancia que nos separa aún de una auténtica situación de igualdad frente a la educación. La democratización de la enseñanza, la eliminación de su carácter clasista, $y$ la iguałdad de oportunidades de todos ante la educación son objetivos a conseguir; pero como ditían los galos de Astérix: "C'est pas demain la veilie». De momento habrá que seguir diciendo, por consiguiente, que el estudiante de $\mathrm{COU}$ ts un estudiante "de clase media para arriba».

\section{LA ELECCIÓN DE CARRERA}

\subsection{Cuando los COU-boys eligen carrera..., o los embotellamientos uni- versitarios del próximo verano.}

La lectura de cerca de un millar de respuestas, en las que los estudiantes de COU indican la catresa o los estudios que piensan seguir a partir del curso próximo, produce una sensación probabiemente similar a la que debe experimentar un responsable de la Jefatura de Tráfico al calcular los embotellamientos previsibles para entrar en la gran ciudad al término de un prolongado fin de semana vetaniego. Cuáles son las pequeñas carxeteras comarcales que van a permanecer descongestionadas, y cuáles las carreteras o autopistas en que los atascos van a ser de mayor envergadura... A semejanza, pues, de las noticias publicadas en los periódicos sobre las colocaciones de conos y las posibles desviaciones de la circulación, he aquí las carreteras que piensan utilizar el próximo octubre 930 estudiantes de COU de Barcelona. La TABLA 5 presenta, en efecto, los resultados obtenidos, y agrupados por Facultades O Escuelas Suptriores.

Aunque debemos ser sumamente precavidos en cualquier intento de generalización de los resultados, en la medida en que no estamos trabajando sobre una muestra representativa, todos los indicios parecen apuntar hacia una persistencia del rusb hacia la carrera de Medicina, que figura en primer lugar en el orden de preferencias de las chicas (emparejada con Filosofía y 
TABLA 5

Estudios elegidos (por Facultades y Escuelas)

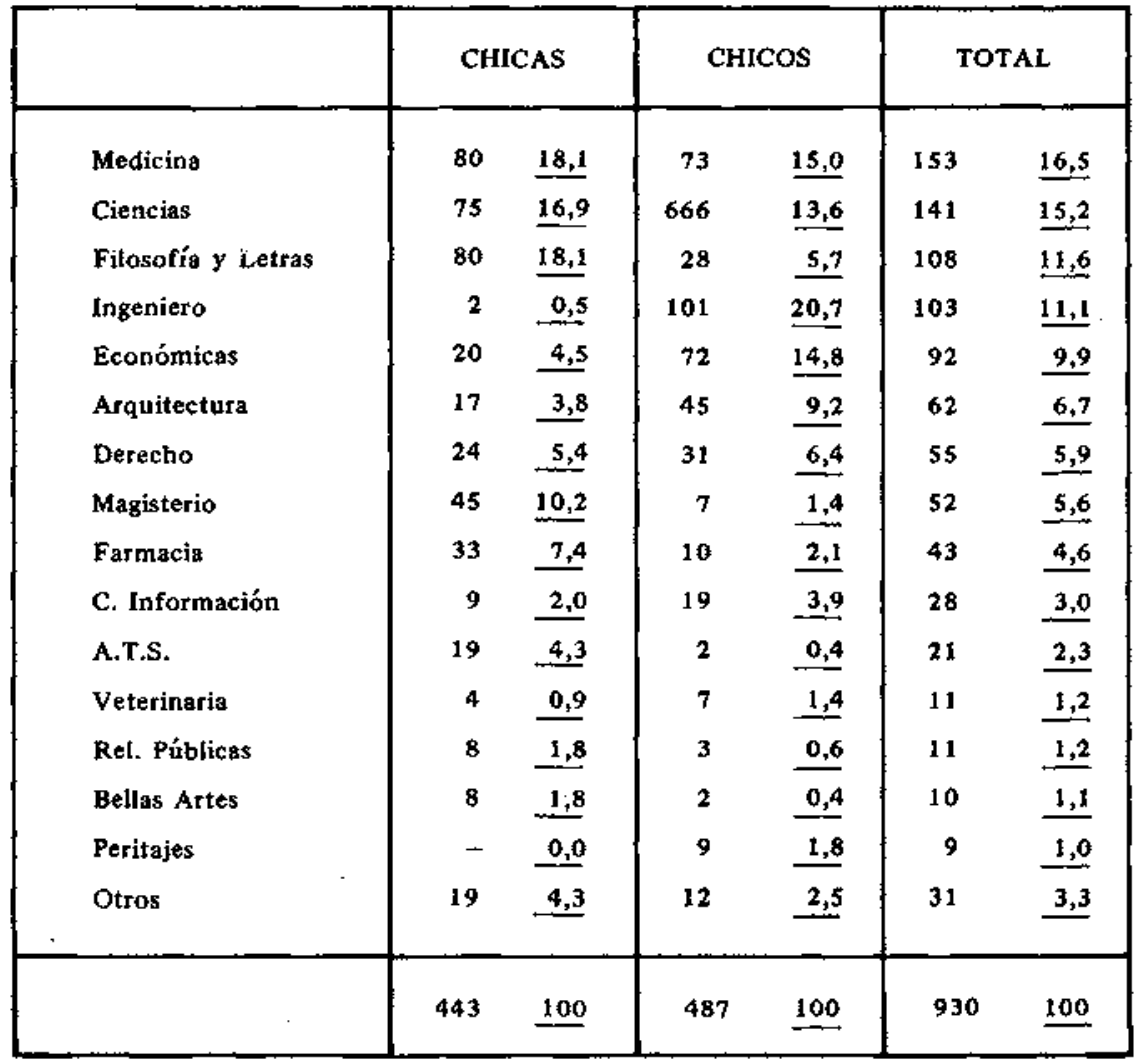

TABLA 5 bis

Estudios Elegidos con mayor Frecuencia

\begin{tabular}{|c|c|}
\hline $\begin{array}{l}\text { Curso } 1974-75 \\
\text { alumnos de COU } \\
\text { (N. 930) }\end{array}$ & $\begin{array}{l}\text { Curso } 1971-72 \\
\text { a partir del número } \\
\text { total de matriculados }\end{array}$ \\
\hline $\begin{array}{l}\text { 1. Medicina } \\
\text { 2. Ciencias } \\
\text { 3. Filosofía y Letras } \\
\text { 4. Ingenieros } \\
\text { 5. Económicas } \\
\text { 6. Arquitectura } \\
\text { 7. Derecho } \\
\text { 8. Magisterio } \\
\text { 9. Farmacta }\end{array}$ & $\begin{array}{l}\text { 1. Filosofía y Letras } \\
\text { 2. Ciencias } \\
\text { 3. Económicas } \\
\text { 4. Medicina } \\
\text { 5. Ingenieros } \\
\text { 6. Derecho } \\
\text { 7. Magisterio } \\
\text { 8. Arquitectura } \\
\text { 9. Farmacia }\end{array}$ \\
\hline
\end{tabular}


Letras) y en segundo lugar (detrás de los estudios de Ingeniero) en el caso de los chicos. Obsérvese que más de la mitad de la población estudiada se inclina por una de estas tres carreras o por la de: Ciencias.

De hecho, y según demuestra la TABLA 5 bis, el orden de preferencia señalado por los estudiantes de COU de nuestro universo no difiere sensiblemente del confeccionado a partit de los alumnos efectivamente matriculados en las distintas Facultades de la Universidad de Barcelona y Escuelas Superiores durante el curso $1971-72 .{ }^{4}$ En efecto, las nueve carretas elegidas con mayor frecuencia son exactamente las mismas en ambos casos, y ni siquiera el número de orden de cada una sufre grandes alteraciones, apteciándose, no obstante, un aumento de la demanda en el caso de los estudios de Medicina y Arquitectura, y un cierto descenso en Filosofía y Letras y Económicas.

Remitiéndonos de nuevo a los datos de la TABLA 5 , y con referencia ahora a la distribución de las opciones según el sexo de los entrevistados, observamos sin sorpresa la pervivencia de unas carreras más «femeninas» -Magisterio, Farmacia, Letras, A.T.S.- y de otras típicamente «masculinas» --Ingenieros e Ingenieros técnicos o peritos, Económicas y Arquitectura.

En cambio, otras carreras antaño consideradas como eminentemente masculinas - las Ciencias en general, la Medicina y también el Derechoaparecen ahora con mayor número de candidatos femeninos que masculinos (en las dos primeras citadas), o bien a un nivel de práctica igualdad (en el caso de los estudios de Derecho). ${ }^{5}$

Estos resultados de la TABLA 5 pueden todavía desglosarse por partida doble: por un lado, subdividiendo las carreras elegidas según las distintas especialidades de que consta cada tipo de estudios (hecho particularmente importante en las Facultades de Letras y de Ciencias, por ejemplo); y por otra parte, analizando la distribución de las opciones en los distintos COU objeto del presente estudio. Con el fin de no indigestar al lector con una gran profusión de datos, ofrecemos a continuación los resultados correspondientes a la primera de las distinciones citadas (TABLA 6),

4. Fuente: Ayuntamiento de Barcelona, Estadf́stica Municipal. Resumen del año 1972,1974 , pp. 178-179.

5. Insistimos nuevamente, sin embargo, en la fiabilidad relativa tan sólo de los datos, en la medida en que trabajamos sobre un universo exclusivamente barcelonés, que no es el único que nutre a la Universidad. No se olvide, por otra parte, que hablamos de preferencias a la hora de elegir una carrera, to cual no significa que todos vayan a cursar efectivamente los estudios ell principio elegidos, ni que todos los que los inicien vayan a concluirlos. 
TABLA 6

Estudios Elegidos, por Especialidades

\begin{tabular}{|c|c|c|c|}
\hline & Total chicas & Total chicos & TOTAL \\
\hline $\begin{array}{l}\text { 1. Medicina } \\
\text { 2. A. T.S. } \\
\text { 3. Farmacia } \\
\text { 4. Veterinaria }\end{array}$ & $\begin{array}{r}80 \\
19 \\
33 \\
4\end{array}$ & $\begin{array}{r}73 \\
2 \\
10 \\
7\end{array}$ & $\begin{array}{r}153 \\
21 \\
43 \\
11\end{array}$ \\
\hline $\begin{array}{l}\text { 5. Biológicas } \\
\text { 6. Química }\end{array}$ & $\begin{array}{l}38 \\
25\end{array}$ & $\begin{array}{l}16 \\
33\end{array}$ & $\begin{array}{l}54 \\
58\end{array}$ \\
\hline $\begin{array}{l}\text { 7. Geología } \\
\text { 8. Físicas } \\
\text { 9. Exactas }\end{array}$ & $\begin{array}{l}2 \\
2 \\
8\end{array}$ & $\begin{array}{r}3 \\
11\end{array}$ & $\begin{array}{r}5 \\
13 \\
11\end{array}$ \\
\hline $\begin{array}{l}\text { 10. Ingenieros } \\
\text { 1 } 1 \text {. Ingenjero técnico } \\
\text { I2. Informática }\end{array}$ & $\begin{array}{l}2 \\
- \\
-\end{array}$ & $\begin{array}{r}95 \\
9 \\
6\end{array}$ & $\begin{array}{r}97 \\
9 \\
6\end{array}$ \\
\hline $\begin{array}{l}\text { 13. Arquitectura } \\
\text { 14. Diseño } \\
\text { 15. Bellas Artes } \\
\text { 16. Artes Gráficas } \\
\text { 17. Música }\end{array}$ & $\begin{array}{r}17 \\
4 \\
8 \\
-\end{array}$ & $\begin{array}{r}45 \\
2 \\
1 \\
3\end{array}$ & $\begin{array}{r}62 \\
4 \\
10 \\
1 \\
5\end{array}$ \\
\hline $\begin{array}{l}\text { 18. Magisterio } \\
\text { 19. Pedagogía }\end{array}$ & $\begin{array}{r}45 \\
8\end{array}$ & $\begin{array}{l}7 \\
2\end{array}$ & $\begin{array}{l}52 \\
10\end{array}$ \\
\hline $\begin{array}{l}\text { 20. Filosofía y Letras } \\
\text { 21. Historia y Geografía } \\
\text { 22. Historia del Arte } \\
\text { 23. Arquéología } \\
\text { 24. Románicas } \\
\text { 25. Ciásicas } \\
\text { 26. Psicología } \\
\text { 27. Sociología } \\
\text { 28. Económicas } \\
\text { 29. Empresariales } \\
\text { 30. Banca }\end{array}$ & $\begin{array}{r}23 \\
4 \\
1 \\
5 \\
8 \\
1 \\
30 \\
4 \\
8 \\
8 \\
1\end{array}$ & $\begin{array}{r}10 \\
3 \\
2 \\
2 \\
1 \\
-8 \\
3 \\
48 \\
21 \\
2\end{array}$ & $\begin{array}{r}33 \\
7 \\
3 \\
7 \\
9 \\
1 \\
38 \\
7 \\
56 \\
29 \\
3\end{array}$ \\
\hline 31. Derecho & 24 & 31 & 55 \\
\hline $\begin{array}{l}\text { 32. Periodismo } \\
\text { 33. Publicidad } \\
\text { 34. Relaciones públicas } \\
\text { 35. Turismo } \\
\text { 36. Idiomas }\end{array}$ & $\begin{array}{l}9 \\
8 \\
5 \\
3\end{array}$ & $\begin{array}{r}17 \\
2 \\
3 \\
1 \\
1\end{array}$ & $\begin{array}{r}26 \\
2 \\
11 \\
6 \\
4\end{array}$ \\
\hline \multirow[t]{2}{*}{ 37. Otras } & 4 & 4 & 8 \\
\hline & 443 & 487 & 930 \\
\hline
\end{tabular}




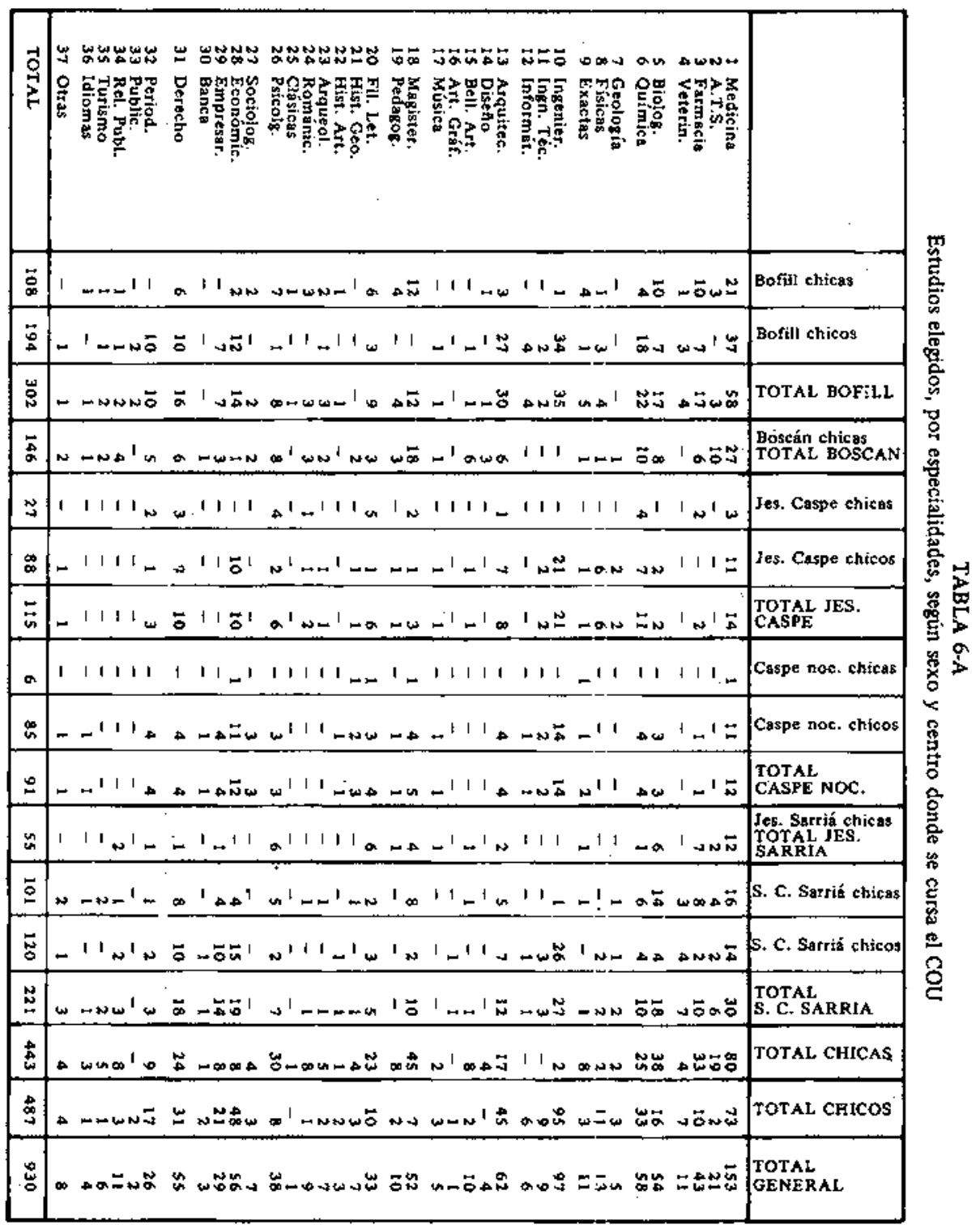


limitándonos por lo demás a unos brevísimos comentatios sobre la distribución por escuelas, cuyos datos completos hallará el lector intetesado en Anexo al presente trabajo (TABLA 6-A).

Obviamente, en ciertas Facultades o Escuelas, los resultados de la TABLA 6 coinciden con los de la anterior (TABLA 5). Tal es el caso de los estudios de Medicina, Arquitectura, Magistetio o Detecho, por ejemplo. En la Facultad de Ciencias de la Información, 26 de los 28 candidatos optan concretamente por estudiar Petiodistno, y sólo 2 por Publicidad. En la Facultad de Económicas, más de la mitad optan por una de las subespeciali. dades de Economia General, cerca de la tercera parte se inclinan por los estudios de Economía de Empresa, y menos de un $10 \%$ sólo por los de Sociología. Más interesante, por su mayor diversidad, es la distribución por especialidades en las Facultades de Filosofía y Letras y de Ciencias. En la primera de ambas sólo dos terceras partes especifican concretamente la especialidad que desean cursar. Y la mitad de éstos se apuntan a los estu. dios de Psicología, con una abrumadora mayoría de chicas. Le siguen en orden de importancia la rama de Historia y Geografía (incluyendo la Ar. queología), con una mayor reptesentación proporcional esta vez del elemento masculino, y la Pedagogía y la Filología (fundamentalmente Románicas), claramente preferidas de nuevo por los alumnos de sexo femenino. En cuanto a la Facultad de Ciencias, las dos especialidades preferidas son indiscutiblemente las de Químicas y Biología ( $80 \%$ del total aproximadamente). $Y$ es cutioso observar que la rama de las Ciencias Biológicas es la que en buena parte explica el hecho, que comentábamos antes, de que sean más las chicas que los muchachos que eligen la carreta de Ciencias: en efecto, para la especialidad de Biología son 38 los aspirantes femeninos frente a 16 chicos solamente. ${ }^{6}$ En Químicas, por el contrario, los candidatos masculinos son más numerosos que los femeninos, e igual ocurre (aunque con cifras absolutas mucho más bajas) con las especialidades de Físicas y Geolo. gia. Paradójicamente, en cambio, la más «científicamente pura» de las ramas de esta carrera, y tradicionalmente la más asociada a unas aptitudes eminentemente masculinas - nos referimos a la especialidad de Ciencias Exactas - es elegida por 8 muchachas frente a 3 chicos tan sólo. Preciso es añadir, con todo, que estas muchachas la escogen en su mayoría con la finalidad de dedicarse posteriormente a la enseñanza, es decir, de con. vertirse en profesoras de matemáticas, y no necesariamente a nivel universitario.

6. En el curso 71.72 , y según la fuente estadística del Ayuntamiento ya citada (p. 179), los alumnos de Biología se repartían mitad por mitad entre chicos y chicas. 
La distribución por escuelas en las que los entrevistados están cursando COU (para mayor detalle puede consultarse la TABLA 6-A, en Anexo) muestra una notable coherencia en las opciones. Así, entre las chicas la carrera de Medicina es elegida en primer lugar en cuatro de los cinco centros; ${ }^{7}$ la única excepcíon la constituye el COU de Caspe, de carácter más netamente literario, como lo atestigua el hecho de que la cartera elegida por mayor número de alumnos sea la de Letras ( $\sin$ especificación de rama) seguida en segundo lugar por la especialidad de Psicología. A Medicina le siguen en orden de importancia Magisterio, que aparece dos veces en segundo lugar (Bofill y Boscán) y una en tercero (Sagrado Corazón). y Biologia, elegida una vez en segundo lugar (Sagtado Corazón), dos en tercero (Bofill y Jesuitas de Sartiá) y una en quinto (Boscán). Entre las cinco primeras opciones se hallan igualmente las carreras de Farmacia y de Letras en su rama de Psicología.

Por lo que respecta a los chicos, los estudios de Ingeniero aparecen casi unánimemente elegidos en primer lugar, salvo en el Bofill, donde son superados por los aspirantes a Medicina. Esta carrera es Ia que ocupa entre los muchachos el segundo lugar en el orden de preferencias, seguida de Económicas (en segundo Iugar en el centro Sagrado Corazón, tercero en Caspe diurno y nocturno, y quinto en el COU Bofill). Aparecen luego, por este mismo orden, los estudios de Arquitectura (con mayor número de candidatos en el Bofill que en los demás centros), Química y Derecho.

Es de destacar que, pese a Ias enormes diferencias que antes observábamos en la población del COU nocturno con respecto a los demás, la elección de carrera se hace según el mismo orden de preferencias: en este centro los estudios elegidos por el mayor número son concretamente, y por este mismo orden: Ingeniería, Medicina y Económicas. Es decir, exactamente el mismo orden en que aparecen elegidos a nivel del conjunto de todos los estudiantes masculinos de nuestro universo.

Finalmente, si comparamos --en esta suerte de «hit-parade" de los estudios de grado superior- las preferencias de chicas y chicos, observaremos que es una sola la que aparece elegida tanto por unos como por otros: Medicina.

Ello da idea, pues, de que en los «previsibles embotellamientos dej próximo veranos a que hacíamos referencía al comienzo de este apartado. la Facultad de Medicina tiene --una vez más- grandes probabilidades de llevarse la palma de los problemas y conflictos. Ojalá este tipo de previsio-

7. No contabilizamos aquí los datos del $\operatorname{COU}$ noturno (chicas) por su exiguo número. 
nes que aquí hemos ensayado a nivel muy local y limitado fueran factibles en gran escala y más a largo plazo, y pudieran tener una eficacia en la tesolución de los problemas. De otro modo seguiremos condenados a contem. plar los atascos, pero impotentes para resolverlos. En efecto, en la circulación como en la enseñanza, los atascos tienen sólo dos soluciones: la construcción de nuevas carreteras o la prohibición de los coches. No patece que culturalmente estemos preparados, en la circulación como en la enseñanza, a una medida prohibitoria (que supondría en el caso de la educación una desmitificación del prestigio de la Universidad y la apertura real de otros cauces); de suerte que la única solución viable a corto plazo parece ser más bien la de construcción de carreteras, en forma de Universidades nuevas, nuevos edificios más amplios, mayor número de profesores, etc. Con. fortados, pues, por semejante ilusión, dispongámonos a sufrir estoicamente el atasco de septiembre de 1975.

\subsection{El estudiante de COU, "¿va a ser lo mismo que papá?»}

Al estudiar el grado de coincidencia de los estudios elegidos con la profesión del padre, observamos que tal coincidencia se da en 123 casos, lo cual representa un 13,2\% del total. Peto, como todos los promedios, tam* bién éste oculta una serie de difetencias notables y bien significativas que analizaremos a partir de dos variables: la carrera elegida y el sexo. ${ }^{8}$

A partir de nuestros datos, "ser como papá» resulta especialmente atrac. tivo cuando "papá» es empresario o abogado (TABLA 7). Un $45 \%$ de los que eligen los estudios de Ciencias Empresariales y un $36 \%$ de quienes se inclinan por Derecho se hallan en tal situación. En el primer caso ello se explica por la conveniencia de que el hijo se haga cargo en el futuro de la empresa o industria actualmente regentada por el padre." La misma razón es válida en el caso de bastantes de los futuros ingenieros, farmacéuticos (o farmacéuticas) y economistas, que aparecen igualmente en Ia TABLA 7 como carreras con un alto grado de coincidencia. La explicación es probablemente distinta, en cambio, en el caso de los estudios de Derecho, donde tienen mayor peso los argumentos de la tradición familiar tomada en un sentido intelectual más que crematístico. A primera vista

8. Por otra parte, y teniendo en cuenta que esta coincidencia sólo puede darse (con raras excepciones) en aquellos casos en que el padre está incluido en las categorías de grado superior o industrial, el porcentaje se elevaría hasta alcanzar un $34,6 \%$ de los hijos de padtes comprendidos en estas dos categorias.

9. Más adeiante, al hablar de las motivaciones de la elección de carreta, se comprobará este extremo. 
TABLA 7

Coincidencia de los Estudios Elegidos con la profesión del padre

\begin{tabular}{|c|c|c|c|}
\hline \multicolumn{2}{|c|}{$\begin{array}{l}\text { Estudios con mayor indice } \\
\text { de coincidencia }\end{array}$} & \multicolumn{2}{|c|}{$\begin{array}{l}\text { Estudios con menor indice } \\
\text { de coincidencia }\end{array}$} \\
\hline 1. Empresariales & $\begin{array}{l}13 / 29^{\circ} \\
44,8\end{array}$ & 1. Biología & $\begin{array}{l}0 / 54 \\
0,0\end{array}$ \\
\hline 2. Derecho & $\begin{array}{l}20 / 55 \\
36,4\end{array}$ & 2. Magisterio & $\begin{array}{l}0 / 52 \\
0,0\end{array}$ \\
\hline 3. Ingeniero & $\begin{array}{l}22 / 97 \\
22,7\end{array}$ & 3. Psicología & $\begin{array}{l}1 / 38 \\
2,6\end{array}$ \\
\hline 4. Arquitectura & $\begin{array}{l}12 / 62 \\
19,4\end{array}$ & 4. Periodismo & $\begin{array}{l}1 / 26 \\
3,8\end{array}$ \\
\hline 5. Medicina & $\begin{array}{l}24 / 153 \\
15,7\end{array}$ & 5. Fitcısofía y Letras & $\begin{array}{l}5 / 108 \\
4,6\end{array}$ \\
\hline 6. Farmacia & $\begin{array}{l}6 / 43 \\
14,0\end{array}$ & 6. A.T'S. & $\begin{array}{l}1 / 21 \\
4,8\end{array}$ \\
\hline 7. Económicas & 12,5 & & \\
\hline 8. Quítrica & $\begin{array}{l}6 / 58 \\
10,3\end{array}$ & & \\
\hline
\end{tabular}

- Las cifras absolutas indican el número de alumnos en cuyo caso se da la coincidencia, sobre el total de estudisntes que eligen la carrera de que se trata. 
podría sorprender el hecho de que los estudios de Medicina no aparezcan en la Tabla que comentamos más que en quinto lugat, con un $16 \%$ de coincidencias, dada la vigencia del estereotipo según el cual la vocación por la Medicina se transmite tradicionalmente con frecuencia de generación en generación. Pero hay que tener en cuenta que, como apuntábamos antes, la carrera de Medicina no es actualmente sólo la elegida por mayor númeto de estudiantes de COU, sino también por alumnos de todos los orígenes so. ciales. Por el contrario, y como veremos en el siguiente apartado, estudios como los de Derecho parecen atraer mayoritatiamente a alumnos de status social muy elevado.

Por lo que respecta a la segunda columna de la misma TABLA 7 (menor grado de coincidencia), es de destacar el hecho de que ninguno de los futuros biólogos (54 en total) ni maestros (52) es a su vez hijo de biólogo o maestro. En el primer caso ello puede explicarse por el carácter relativamente reciente de los estudios de Biología, pero la explicación no es válida para los maestros, cuyos hijos eligen en todo caso carreras completamente distintas de las de sus padres. ${ }^{10}$ Tampoco los estudios de Periodismo ni los de Letras en general - y de Psicología en particular- arrojan elevados porcentajes de estudiantes que quieran continuar una tradición familiar."

En general, los casos de coincidencia de estudios con la profestón del padre se dan sobre todo en los hijos varones. Las chicas parecen en este sentido más ajenas a esta influencia de la carrera o profesión paterna a la hora de optar ellas por unos estudios superiores.

Así, por ejemplo, en el COU Bofill la media de coincidencias es de un $17 \%$, pero se distribuye entre un $12 \%$ en el caso de las chicas y un $20 \%$ en el de los chicos. Asimismo, los COU Boscán y de los Jesuitas de Satriá, de composición exclusivamente femenina en nuestro universo, arrojan unos porcentajes de coincidencia mucho más bajos que el del conjunto de la población (respectivamente $8,2 \%$ y $3,6 \%$ frente al $13,2 \%$ del total

10. Decimos completamente distintas porque no sólo no eligen Magisterio, sino tampoco la especialidad de Pedagogía o Ciencias de la Educación en la Facultad de Letras, ni, en general, ninguna carrera cuya orientación profesional sea ptimordial. mente la de la enseñanza.

11. Lógicamente la lista de carteras en las que el grado de coincidencia es nulo - casi nulo podría alargarse de modo considerable si las tomáramos todas en cuenta. Así, por ejemplo, la coincidencia es nula entre los candidatos a estudiar Físicas, Exactas, Bellas Artes, Música, Sociología, etc. Para no alargat excesivamente la relación y para que los datos tuvieran una mínima significatividad hemos adoptado como criterio el de no incluir en la relación más que aquellas carreras que fueran elegidas por un mínimo de veinte estudiantes en total. 
del universo). Finalmente, en el COU nocturno de Caspe el porcentaje es igualmente muy bajo $(3,3 \%)$, lo cual se explica aquí, obviamente, por el origen social de los estudiantes de este centro (cf. supra, TABLA 4).

\subsection{De los condicionamientos sociales de la vocación.}

$\mathrm{El}$ análisis de los casos de coincidencia entre estudios elegidos y profesión del padre no constituye sino un aspecto particular de una cuestión más general y sociológicamente más relevante, a sáber, la existencia de ciertas relaciones entre la elección de cartera y la pertenencia a unos grupos sociales determinados. Los ya célebtes trabajos de sociología de la educación Ilevados a cabo por el equipo de Bourdieu en Francia han puesto de relieve hasta qué punto la supuesta autonomía del individuo en la elección de unos estudios determinados no es sino un mito, consolador quizás, pero engañoso a fin de cuentas. ${ }^{12}$ Consciente o inconscientemente, en efecto, una serie de condicionanientos sociales limitan la supuesta libertad del individuo para seguir lo que genéticamente suele designarse con el término de vocación; más aún, es el propio despertar de esta vocación el que de entrada viene ya condicionado socialmente.

Vamos a examinar aquí sucintamente estos condicionamientos sociales poniendo en relación dos variables: los estudios elegidos por los estudiantes de COU y la categoría socio-profesional de sus padres. ${ }^{13}$

La TABLA 8 presenta los resultados del cruzamiento de ambas variables, entre los que destacan los siguientes:

a) el grupo de hijos de obreros $(10,4 \%$ del total) obtiene porcentajes superiores a esta media en seis ocasiones: Peritajes $(22,2 \%)$, Magistetio $(21,2 \%)$, A.T.S. $(19,0 \%)$, Filosotia y Letras $(14,8 \%)$, Económicas

12. Cf. especialmente dos publicaciones de Bourdieu, fruto de tales investiga. ciones: Les béritiers y La reproduction, Paris, Ed. de Minuit, 1964 y 1970.

13. Cabría igualmente ponet en relación los estudios elegidos con el lugar de origen del estudiante, efectuados todos los cálculos, sin tmbargo, y ante la ausencia de resultados especialmente significativos, preferimos no alargar el texto innecesariamente. Digamos únicamente que en el análisis de nuestro universo se observa una mayor tepresentación de los catalanes entre los candidatos a estudiar Letras, de catalanes y en especial barceloneses entre los futuros arquuitectos, de no barceloneses entre los futuros economistas, y de no catalanes entre los aspirantes a la carrera de Derecho. Las carreras de Ciencias e Ingeriería son elegidas en proporciones idénticas a las de la población total del universo, Medicina artoja unos porcentajes elevados de no catalanes y de extranjeros, y finalmente, los quie eligen Magisterio no proceden, como hubiese cabido esperar quizás, de "provincias" más que de Barcelona capital. 
TABLA 8

Estudios elegidos y categoría socio-profesional del padre

\begin{tabular}{|c|c|c|c|c|c|c|c|}
\hline & Obrero & Empleado & Comercio & $\begin{array}{l}\text { Grado } \\
\text { Medio }\end{array}$ & $\begin{array}{r}\text { Gra } \\
\text { Supe }\end{array}$ & industr. & TOTAL \\
\hline Medicina & ${ }_{18}^{18} \frac{11,8}{, 6}$ & $\int_{15,2}^{22}$ & $35 \frac{22,9}{16,3}$ & $\begin{array}{l}14 \quad \underline{9,2} \\
\underline{11,9}\end{array}$ & $46 \quad 21 \frac{30,1}{1}$ & $18 \frac{11,8}{13,1}$ & $\begin{array}{c}153 \\
16,5\end{array}$ \\
\hline Ciencias & $12 \quad 8,5$ & $24 \quad 17,0$ & $\underline{24,1}$ & $\underline{14,9}$ & $\underline{20,6}$ & 14,9 & $141 \quad 100$ \\
\hline Fil. y Letr. & $16 \underset{16,5}{\frac{14,8}{5}}$ & is $10 \frac{13,9}{3}$ & 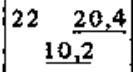 & $12 \frac{11,1}{10,2}$ & $29 \quad \frac{26,9}{\underline{13,3}}$ & $14 \frac{13,0}{10,2}$ & $108 \underline{100}$ \\
\hline Ingeniero & $8 \underset{8,2}{7,8}$ & $20 \quad \frac{19,4}{13,8}$ & $24 \pm \frac{23,3}{ \pm 1,2}$ & $\operatorname{li}_{13} \frac{12,6}{1,0}$ & $23 \frac{22,3}{10,6}$ & $\begin{array}{c}15 \\
10,9\end{array}$ & $103 \underset{11,1}{100}$ \\
\hline Económicas & $12 \frac{13,0}{12,4}$ & ${ }_{11}^{17} \frac{18,5}{7}$ & $22 \frac{23,9}{10,2}$ & $5 \quad \frac{5,4}{4,2}$ & $\begin{array}{ll}1 \mathrm{I} & \underline{12,0} \\
& \underline{\underline{5}, 0}\end{array}$ & ${ }^{25} \underline{18,2}$ & $92 \quad 100$ \\
\hline Arquitect. & ${ }_{4}^{4} \underset{4, I}{6,5}$ & $9 \underline{6,2,2}$ & $12 \quad \underline{\underline{5,6}}$ & $\begin{array}{ll}19 & \frac{30,6}{16,}\end{array}$ & $\begin{cases}1 \mathrm{I} & \frac{17,7}{5,0}\end{cases}$ & $7 \underset{5,11,3}{11}$ & $62 \underset{6,7}{100}$ \\
\hline Derecho & ${ }_{2} 2, I^{3,6}$ & $6 \quad \underline{4,10,9}$ & $9 \frac{16,4}{\underline{4,2}}$ & $6 \quad \frac{10,9}{5,1}$ & $26 \quad \frac{47,3}{\perp 1,9}$ & $6 \frac{10,9}{4,4}$ & $55 \underline{100}$ \\
\hline Magisterio & 1 I $\frac{21,2}{11}$ & $9 \underset{6, \underline{17,3}}{\underline{2}}$ & $14 \quad \underline{\underline{26,9}}$ & $6 \quad \frac{11,5}{5,1}$ & $5 \quad \underline{2,3,6}$ & $7 \underset{5, I}{13,5}$ & $52 \underset{5,6}{100}$ \\
\hline Farmacia & $\begin{array}{l}1 \quad \underline{2,3} \\
\underline{1,0}\end{array}$ & ${ }^{3} \quad \underline{2,1}, \underline{\underline{7,0}}$ & $\begin{array}{ll}11 & \underline{25,6} \\
\underline{5, I}\end{array}$ & $\begin{array}{l}4, \underline{9,3} \\
\underline{3,4}\end{array}$ & $16 \quad \frac{37,2}{7,3}$ & $8 \underline{s, 8}$ & $43 \underset{4,6}{100}$ \\
\hline c. Inform. & $2 \underset{2,1}{\frac{7,1}{1}}$ & $5 \quad \frac{17,9}{\underline{3,4}}$ & $9 \quad \frac{32,1}{4,2}$ & $4 \quad \frac{14,3}{3,4}$ & $\begin{array}{ll}5 & \frac{17,9}{2,3} \\
& \end{array}$ & $3 \quad \frac{10,7}{2,2}$ & $28 \quad \underline{100}$ \\
\hline A.T.S. & $4 \frac{19,0}{4,1}$ & $5 \quad \frac{23,8}{3,4}$ & $3 \quad \frac{14,3}{1,4}$ & $2 \quad \frac{9,5}{1,7}$ & $3 \quad \frac{14,3}{1,4}$ & $4 \quad \frac{19,0}{2,9}$ & $21, \underline{2,3}$ \\
\hline Veterinaria & $-\underline{0,0}$ & $10 \underline{0,7}$ & $20 \frac{18,2}{0,9}$ & $10, \underline{9, I}$ & $4 \frac{36,4}{1,8}$ & $3 \underset{2,2}{\underline{27,3}}$ & II $1, \underline{100}$ \\
\hline Rel. Públ. & $1 \frac{9,1}{\underline{1,0}}$ & $2 \frac{18,2}{\underline{1,4}}$ & $4 \underset{I, 9}{\underline{36,4}}$ & $2 \frac{18,2}{1,7}$ & $1 \underset{\underline{0,5}}{\underline{9,5}}$ & $I_{0,7}^{\underline{9,1}}$ & Ii 1,2 \\
\hline BeIl. Artes & $1 \quad \frac{10,0}{1,0}$ & $-\underset{\underline{0,0}}{\underline{0,0}}$ & $2 \quad \frac{20,0}{\underline{0,9}}$ & $2 \frac{20,0}{1,7}$ & $4 \frac{40,0}{1,8}$ & $1 \quad \underline{0,70,0}$ & $10 \underset{1,1}{100}$ \\
\hline Peritajes & $2 \frac{22,2}{\underline{2, I}}$ & $2 \frac{22,2}{\underline{x}, 4}$ & $10 \frac{1 d_{1}}{\underline{0,5}}$ & $3 \quad \frac{33,3}{\underline{2,5}}$ & $-\underset{\underline{0,0}}{\underline{0,0}}$ & I $\frac{I 1,1}{0,7}$ & $9 \underline{1,00}$ \\
\hline Otros & $3 \quad \underline{3,1}$ & $5 \quad \underline{3,4}, \underline{4}$ & $11 \quad \underline{35,5}$ & ${ }^{4} \frac{12,9}{3,4}$ & $5 \quad \frac{16,1}{\underline{2,3}}$ & $\begin{array}{l}3 \underline{2,2} \\
\underline{9,7}\end{array}$ & $31 \underline{3,3}$ \\
\hline & ${ }^{97} \underline{100,4}$ & $\begin{array}{c}145 \quad 15,6 \\
100\end{array}$ & $\mid \begin{array}{cc}215 & \underline{23,1} \\
\underline{100}\end{array}$ & $\begin{array}{cc}118 & 12,7 \\
100\end{array}$ & $\begin{array}{c}218 \quad 23,4 \\
100\end{array}$ & $\begin{array}{c}137 \quad 14,7 \\
\underline{100}\end{array}$ & $\underline{100}^{930}$ \\
\hline
\end{tabular}


$(13,0 \%)$, y Medicina $(11,8 \%) .^{14}$ Se observatá que las tres primeras coin. ciden precisamente en ser carreras de grado medio.

b) el grupo de hijos de empleados constituye el 15,6\% del total. De nuevo aparecen con potcentajes más elevados los estudios de A.T.S. $(23,8 \%)$ y Peritaje $(22,2 \%)$, seguidos esta vez de Ingeniería y Económicas.

c) el grupo de los hijos de comerciantes e independientes se distribuye con relativa uniformidad, pero alcanza vértices más elevados en cier. tas profesiones nuevas o poco usuales: Relaciones Públicas, Ciencias de la Información, y aquéllas que aquí hemos agrupado con el título genético de Otros.

d) los hijos de miembros de las profesiones liberales con título de grado superior $(23,4 \%$ en total) contrastan claramente con los grupos anteriores. En efecto, los porcentajes más elevados Ios obtienen aquí los estu dios de Derecho $(47,3 \%)$, Beilas Artes $(40 \%)$, Farmacia $(37,2 \%)$, Veterinaria $(36,4 \%)$ y Medicina $(30,1 \%)$.

Los condicionamientos sociales a que antes hacíamos alusión juegan, pues, ya a ese nivel y a pesar del número relativamente reducido de casos sobre el que a veces trabajamos. La «vocación» al Magisterio puede ser a veces una «vocación» a cursar una carrera más corta; la «vocación» a los estudios de ATS cobra las apariencias de una «vocación a la Medicina para clases no privilegiadas», etc., mientras que en el extremo opuesto las «vocaciones» jurídicas o artísticas parecen exigir como presupuesto previo un status económico elevado.

Las carretas de Ciencias y de Ingeniería son las que ofrecen una repartición por categorías socio-profesionales más próxima de la media, es decir, con menores desviaciones. ${ }^{15}$ En la Facultad de Letras la distribución es asimismo muy regular, salvo por to que tespecta al grupo de los obreros, que aparece ligeramente super-representado. Con porcentajes también más elevados figuran los hijos de titulados de grado superior en las carteras de Medicina y Farmacia. En el caso de Económicas se combinan una infra. representación del grupo de grado superior con una super-representación de hijos de industriales (debida sobre todo a los estudios empresariales concretamente). Finalmente, en la carrera de Magisterio es muy notable la diferencia entre las categorías de obtetos y de grado superior, mientras que el mismo fenómeno se reproduce, aunque con signo exactamente opuesto,

14. Véanse para ello los porcentajes situados a la derecha de las cifras absolutas. en la TABLA que comentamos.

15. Véanse los porcentajes situados debajo de las cifras absolutas, en la TABLA 8. 
en Ia carreta de Derecho, donde el escaso porcentaje de obreros se acompaña de un porcentaje muy notable en la categoría de grado superior.

El test estadístico del chi cuadrado confirma los comentarios que anteceden. Estos son, en efecto, los valores obtenidos para las nueve carteras con más de cuarenta aspirantes ${ }^{16}$ :

Ingeniero, 1.93

Ciencias, 2.11

Filosofía y Letras, 3.99

Medicina, 6.80

Farmacia, 9.61
Magisterio, 11.15

Derecho, 19.47

Arquitectura, $19.79^{17}$

Económicas, 21.95.

En seis de los nueve casos (cinco, si exceptuamos Arquitectura), podemos hablar, pues, de la existencia de una relación estadísticamente significativa entre la elección de carrera y la categoría socio-profesional del padre. De estas cinco carreras, tres aparecen asociadas a la posesión de un status socio-económico elevado (Medicina hasta cierto punto, Farmacia y sobre todo Derecho), una se vincula más específicamente al tipo de ocupa. ción -empresario o industrial- del padre (C. Económicas), y la quinta queda como recurso de los sectores sociales menos privilegiados (Magisterio).

La libertad de elección de carrera es, por lo tanto, una libertad tan sólo relativa, según apuntábamos al comienzo. Ahora bien, las limitaciones a que se ve sometida están habitualmente hasta tal punto interiorizadas que se mantienen en el nivel de lo inconsciente. De ahí que al preguntar a los entrevistados por los motivos que les han inducido a optar por uno u otro tipo de estudios, rara vez aparezcan razones ligadas al propio status social del estudiante. Aparentemente, por el contrario, la elección de cartera es subjetivamente percibida por los afectados como una opción personal y como un acto perfectamente libre y deliberado, al menos en la inmensa mayoría de los casos. A esta cuestión vamos a teferirnos a continuación, en la parte final del trabajo.

16. El chi cuadrado se ha calculado en cada caso contraponiendo al grupo que elige una carrera determinada con el resto del universo. Teniendo, pues, un grado de libertad, el umbral de significación se sitúa en 6.63 (valor de $\mathrm{X}^{2}$ ) con una probabilicad del $99 \%$.

17. Pese a su elevado vaior el dato nos parece en esta ocasión poco fiable, en vista de que la única categoría que se distingue de Jas demás es la de grado medio, sin que quepa hallar ante este hecho explicación plausible alguna. 
TABLA 9

Razones aducidas para elegir estudios (cifras absolutas)*

\begin{tabular}{|c|c|c|c|}
\hline & CHICAS & CHICOS & TOTAL \\
\hline Mis aptitudes & 27 & 75 & 102 \\
\hline Interés individual & 17 & 39 & 56 \\
\hline Me gusta, afición, inclinación hacia & 278 & 324 & 602 \\
\hline Vocación & 15 & 22 & 37 \\
\hline Autorrealización, me llena & 36 & 31 & 67 \\
\hline Darse a los demás, entregarse & 17 & 16 & 33 \\
\hline Ayuda a los demás, servicio & 52 & 39 & 91 \\
\hline Mejorar la sociedad, proyección social & 27 & 27 & $\$ 4$ \\
\hline Relación con los demás & 24 & 7 & 31 \\
\hline Profesión humana & 20 & 14 & 34 \\
\hline Profestón interesante & 44 & 28 & 72 \\
\hline Futuro, importancia de la profesión & 15 & 25 & 40 \\
\hline $\begin{array}{l}\text { Salidass de la profesión, me sitúa } \\
\text { (razón económica latente) }\end{array}$ & 21 & 42 & 63 \\
\hline Profesión en la que queda mucho por hacer & 4 & 4 & 8 \\
\hline Creatividad & 4 & 9 & 13 \\
\hline Adqquisición, ampliación de conocimientos & 29 & 22 & 51 \\
\hline La investigación (importancia de, me gusta...) & 46 & 32 & 78 \\
\hline La enser̃anza (me gusta) & so & 14 & 64 \\
\hline Me gustan los niños & 34 & 2 & 36 \\
\hline Me gustan los animales, la naturaleza & 13 & 12 & 25 \\
\hline Razones familiares & 22 & 59 & 81 \\
\hline Razones económicas & $s$ & 28 & 33 \\
\hline $\begin{array}{l}\text { Pese al probiema de las salidas; no tengo } \\
\text { en cuenta lo económico }\end{array}$ & 4 & 7 & 11 \\
\hline $\begin{array}{l}\text { No ánimos, ganas o posibilidad de hacer una } \\
\text { carrera larga, universitaria }\end{array}$ & 12 & 4 & 16 \\
\hline No lo sé & - & 2 & 2 \\
\hline No contesta & 2 & 2 & 4 \\
\hline \multirow[t]{2}{*}{ Otros } & 1 & 5 & 6 \\
\hline & 819 & 891 & 1.710 \\
\hline
\end{tabular}

- Los totales son superiores a los de fa población que compone el universo, dado que cada entrevistado podía aducir varias razones a la vez. 
TABLA 10

Motivaciones más frecuentes, por escuelas (en \%)*

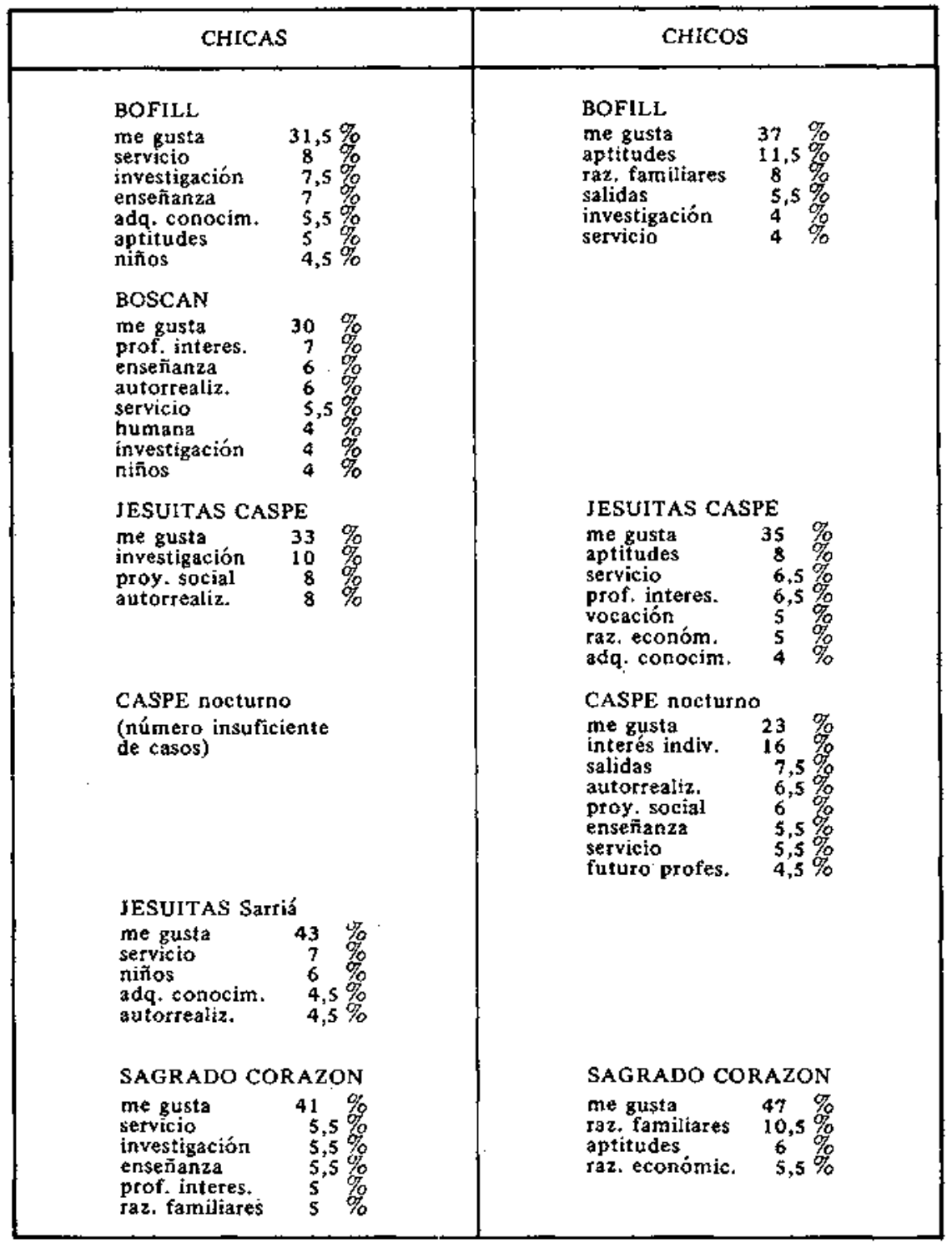

* Los porcentajes no están calculados sobre el total de la población estudiada, sino sobre el total de los motivos aducidos, ya que to que nos interesaba detectar era en este caso et peso de cada una de las motivaciones en el conjunto de todas ellas. Por otra parte, los porcentajes no suman 100 , puesto que se mencionan sólo las que aparecea con mayor frecuencia (como norma se han incluido sólo aquellas que representaban como mínimo un $4 \%$ del total). 


\section{Racionazizando la elección DE CARReRA}

\subsection{Los motivos percibidos como determinantes de la opción.}

Reconozcamos de entrada que no es fácil responder a una pregunta formulada a bocajarro sobre las razones que han inducido a una persona a cursar determinado tipo de estudios. Normalniente estas tazones serán múltiples y complejas, contradictotias a veces, no siempre conscientes, y a menudo difíciles de racionalizar. De ahí que no deba sorprender el que la razón más frecuentemente aducida sea simplemente: «Porque me gusta», respuesta que combina indudablemente una parte de verdad con un deseo de no verse obligado justamente a racionalizar algo que raras veces es una decisión puramente racional, y que en ciertas ocasiones puede ser el equivalente elegante de un abierto: «iDéjeme usted en paz!».

Por esta misma dificultad que entraña la pregunta $-y$, por ende, su interpretación- se optó por agrupar las respuestas en unas categotías deliberadamente simples, que pretenden apuntar a la prioridad dada a un motivo o tipo de motivos determinado, con relativa independencia de la forma peculiar de expresarlo.

Aunque lógicamente muchas de las razones aducidas son función de una carrera determinada, ${ }^{18}$ la TABLA 9 presenta globalmente la lista de tales motivos, con su distribución de frecuencias entre las chicas, por un lado, y los chicos por otro, mientras que en la TABLA 10, que comentaremos simultáneamente, se especifica la distribución por escuelas en aquellas motivaciones que en cada caso aparecen con mayor frecuencia.

\section{«is aptitudes».}

Se agrupan en esta categoría las razones que giran en torno a la capacidad personal de cursar los estudios elegidos. Factor tenido más en cuenta por los chicos que por las chicas en general, aparece valorado sobre todo en el COU Bofill (incluso por las chicas en este caso) y Caspe (pero no en el curso nocturno), y asociado a las carreras de Ingeniero, Arquitecto, Químico y Derecho entre los muchachos, y Lettas y otra vez Química y Dere-

18. Así por ejemplo, y salvo en casos como el «me gusta» ya citado, la motivación «investigación» irá lógicamente ligada a estudios de carácter más científico, mientras que las respuestas «me gusta la enseñanza» o «me gustan los niños» se asociarán mormalmente a la carrera de Magisterio o los estudios de Pedagogia, etc. 
cho entre las chicas. Globalmente es el motivo aducido con mayor frecuencia después del mayoritatio «me gusta».

«Interés individual».

Con este título se han englobado aquellos casos en que los entrevistados manifestaban tener razones muy personales, pero no de tipo específicamente familiar o económico, para cursar unos estudios determinados. Es éste un argumento que únicamente en el COU nocturno de Caspe cobra gran importancia numérica y que básicamente se asocia a las carreras de Económicas (tanto en la rama de Economía general como en la de Empresariales) y de Ingeniería. Cabe preguntarse hasta qué punto no se trata en realidad de una motivación pecuniaria subyacente, pero encubierta de forma consciente o inconsciente con el fin de aparentar una decisión personal y muy madurada.

«Me gusta».

Como ya hemos señalado, es ésta la respuesta que -en sus distintas expresiones: «Siento inclinación hacia», «tengo afición por», «me atrae», etcétera. - se da con mayor frecuencia, en todos los casos, para todas las carreras y para todas las escuelas. En todas ellas, en efecto, es la que aparece en primer lugar, con un porcentaje normalmente muy superior a todas las demás. Las dos terceras partes de los entrevistados (tanto chicos cono chicas) dan esta razón como la determinante o una de las determinantes de su elección. El carácter masivo e indiscriminado de la respuesta impide ptecisamente en este caso apreciar diferencias significativas según las distintas categorías del universo y los distintos tipos de estudios escogidos. Acaso cupiera sólo mencionar el hecho de que en el Caspe nocturno, aún siendo igualmente la que figura en primer lugar, alcanza esta respuesta un porcentaje sensiblemente más bajo que en los demás centros.

\section{"Vocación».}

Sólo se han incluido en esta categoría quienes expresamente hacían mención de la palabra, significativa por cuánto corresponde a un estereotipo culturalmente muy difundido. En este sentido es de destacar el número francamente reducido de personas que utilizan el término (37 en total), confirmado por el hecho de que en una sola escuela (Caspe, chicos) aparece entre las motivaciones más frecuentes, con un valor de un $5 \%$. Por otra 
parte, la asociación a determinadas carreras es aquí clatísima: tecurren a la expresión los aspirantes masculinos a estudiar Medicina, y las chicas que eligen Medicina y Magisterio. Ello coincide además en buena parte con el estereotipo cultural al que antes aludiamos, y según el cual se ve en ambos tipos de estudios a aquéllo para lo que decididamente «hay que tener gran vocación».

\section{«Autorrealización».}

Relativamente próxima en el fondo a la categoría anterior («vocación»), incluye ésta aquellos casos en los que la respuestia da, de alguna manera, prioridad al «yo»: los estudios futuros percibiclos como legitimación de una postura y unas actitudes personales, como una justificación, como algo que debe satisfacer íntimamente, «llenar» o conferir significación a la vida y actuación del entrevistado; de ahí el término de «autorrealización» con el que hemos intentado sintetizarlo. Curiosamente, las carreras a las que va asociada esta motivación son básicamente las mismas que en el caso anterior: Medicina (chicos) Medicina y Magisterio (chicas). Pero la razón es dada con mayor frecuencia (el doble), y por las chicas más que por los chicos; entre las primeras deja de aparecer sólo en el Bofill y el Sagrado Corazón, mientras que en los segundos se halla sólo en el COU nocturno.

«Darse a los demás».

Seguimos con un tipo de motivos en los que el «yo» desempeña un papel importante, pese a que a nivel del discurso nos hallamos ante la motivación más hondamente altruista en apariencias. $\mathrm{Y}$ de nuevo las mismas profesiones que en los apartados anteriores (a las que se añade esta vez, entre las chicas, la de ATS) son las que se vinculan a este deseo de «entrega» a los demás. No se trata, con todo, de una razón dominante en ninguno de los centros estudiados, y es comúrı a ambos sexos (cínicamente se diría quizás que porque es una motivación no ligada al sexo sino a la edad).

«Ayuda a los demás».

La única diferencia entre esta categoría y la antetior estribaría en un problema de gradación; el «yo» desempeña aquí un papel menos importante, y la voluntad de "servicio» o «ayuda» es menos exageradamente altruista que la de «entrega». Cuantitativamente es ésta la tercera de las motiva- 
ciones por orden de importancia, y aparece en cuatro de los cinco grupos femeninos y en tres de los cuatro masculinos, aunque normalmente con porcentajes algo más reducidos entre éstos. Nuevamente se repiten las mismas carreras: Medicina en el caso de los muchachos, y Medicina, Magisterio ( $y$ secundariamente Psicología esta vez) en el de las muchachas.

«Mejorar la sociedad».

El altruísmo cobra aquí una nueva dimensión, más colectiva o social. El estudiante se percibe menos aquí en situación de enfrentamiento a unos individuos que a toda la colectividad, para proponerse su consiguiente mejora o transformación. El estereotipo querría seguramente que fuera ésta una motivación típicamente masculina, pero ello no es así. Por otra parte, el cambio de perspectiva se refleja igualmente en el tipo de estudios para los que se aduce semejante razón: con la excepción de Magisterio, que aparece de nuevo entre las chicas en esta ocasión, las carreras percibidas como de mayor «proyección social» son el Derecho (chicos y chicas), y entre los chicos, además, la Economía y la Sociología.

«Relación con los demás».

El altruísmo que antes comentábamos se convierte aquí en un argumento presentado con la mayor neutralidad posible; no se trata ya de «darse» al otro o de «ayudarle» sino simplemente de «conocerle» y «entrar en relación con él». Presentado con mucha mayor frecuencia por las chicas que por los chicos, semejante argumento es esgrimido sobre todo en favor de los estudios de Psicología, de Relaciones públicas, y también de Medicina.

«Profesión bumana».

En ciertos casos se aduce como motivo para elegir una carrera el hecho de tratarse de una «profesión muy humana». Ello sucede básicamente con una sola carrera, la de Medicina.

«Profesión interesante».

Una gran diversidad de estudios son considerados «interesantes» y ele. gidos por tal motivo por los entrevistados; en esta ocasión, además, no coinciden en absoluto chicos y chicas. Los primeros juzgan especialmente inte- 
resantes las carreras de Ingeniero, Derecho y Empresariales; las segundas, en cambio, se refieren principalmente a Psicología, Biología, Farmacia, Bellas Artes y Relaciones Públicas. Se trata, por lo demás, de un argumento esgrimido sobre todo por chicas (del Boscán y Sagrado Corazón en particular).

«Futuro o importancia de la profesión».

Las profesiones «más importantes» o con «mayor futuro» serían según nuestros datos las de ingeniero y economista para los chicos, y las de mé. dico y maestra para las chicas (que de todos modos insisten menos en este argumento). S6́lo en un caso este motivo figura entre los principales dentro de un mismo centro de enseñanza: en el curso nocturno de Caspe, que una vez más se distingue de todos los demás.

«Las salidas de la profesión».

En la mayoría de los casos quienes aducen como tazón la de las salidas están refiriéndose implícitamente a la solución del problema económico. De ahí que, pese a todas las emancipaciones femeninas habidas y por haber, siga siendo éste un argumento típicamente masculino, de quien asume la idea de que como futuro «cabeza de familia» va a tener que responsabilizarse de su sustento. En ninguno de los grupos de chicas de la TABLA 10 aparece este motivo como uno de los más citados. P’or otra parte, las carreras con mayores «salidas» o que mejor han de permitir «situarse» son las de Ingeniería, Económicas y Empresariales entre los chicos, y la de Farmacia entre las muchachas.

«Profesión en la que queda mucho por bacer».

Son muy pocos los que formulan de esta manera el argumento de la importancia de una profesión, subrayando así su novedad y la necesidad de su desarrollo. Pero merece destacarse que las cuatro chicas que afirman haber optado inducidas por esta razón coinciden en la elección de carrera: la Biología.

\section{«Creatividad».}

También éste es un motivo aducido en escasas ocasiones (aunque más bien por muchachos), y en el que hay una gran coincidencia de criterio: 
los estudios de Periodismo serían según ellos los más adecuados para posibilitar la expresión de esta cualidad en boga que es la creatividad.

\section{*Adquisición de conocimientos».}

Argumento no altruísta peto si desintetesado y con pocas pretensiones de «situarse», era previsible que se incluyeran en esta categoría más chicas que chicos (especialmente de status socio-económico elevado), y con opciones por carretas de las llamadas «humanísticas». Efectivamente, tanto entre los muchachos como las muchachas la cartera de Filosofía y Letzas en sus distintas tamas (y en particular la de Psicología) es la que apatece casi sistemáticamente asociada a este tipo de motivación.

\section{«La investigación».}

La importancia de la investigación y el interés por dedicarse a ella ocupan en nuestro universo uno de los lugates destacados. Paradóficamente (si nos atenemos a lo que antes denominábamos estereotipos culturales) son más las chicas que los chicos que hacen intervenir este interés investigador para justificar su elección de carrera (46 y 32 respectivamente). En cuatro de los cinco grupos de la TABLA 10 aparece este motivo, que entre los muchachos se halla presente sólo en el caso del J. Bofill. En cuanto a las carreras vinculadas a esta categoría, se trata sobre todo de la Biología y la Química, amén de la Farmacia entre las chicas y la Medicina en el caso de los muchachos.

\section{«La enseñanza».}

Se trata de una motivación relativamente frecuente, mayoritariamente femenina, y muy ligada lógicamente a las carretas de Magisterio y de Letras (aparte de las Ciencias Exactas entre las chicas, si bien las cifras absolutas son en este caso muy bajas). Una vez más, su presencia entre las más frecuentes en el COU nocturno de Caspe diferencia a este grupo de sodos los demás (masculinos) que integran el universo.

«Los niños».

Estrechamente ligada a la anterior, esta categoría que aparece en tres de los cinco grupos femeninos, es casi exclusivamente femenina y se halla intimamente vinculada a la elección de la carrera de Magisterio. 
«Amor a los animales o a la naturaleza».

Biología y Veterinaria son los únicos estudios susceptibles de ser elegidos por quienes (chicos y chicas en proporciones semejantes) anteponen esta motivación a todas las demás.

«Razones familiares».

En estrecha conexión con lo que comentábamos en el apartado 4.2, se agrupan en esta categoría cuantos reconocen como motivo para cursar unos estudios determinados la existencia de una telación con la profesión ejercida por sus padres. De ahí que sean mucho más numerosos los chicos que las chicas ( 59 y 22 respectivamente), y que sea una de las motivaciones cuantitativamente más importantes (especialmente en el COU del Sagrado Cotazón, y también entre el alumnado masculino del Bofill; no así, por supuesto, en el COU nocturno). Las catreras en las que mayor incidencia tienen estas razones familiares son las de Ingeniería (chicos), Medicina (chicos y chicas), Empresariales (ambos igualmente), Farmacia (chicas), Economía y Arquitectura (chicos), y Detecho (chicos y chicas).

«Razones económicas».

Son pocos los que explícitamente aluden a esta cuestión para justificar su elección de carrera, fundamentalmente muchachos (por lo ya apuntado al hablar de «las salidas de la profesión»), y con tnas opciones perfectamente delimitadas: Económicas y Empresariales, Ingenierrías, y secundatiamente Medicina.

«Pese al problema de las salidas económicas».

Planteamiento exactamente opuesto al del caso anteriot, mencionan tan sólo esta cuestión (y no sin fundamento) algunos de los que han optado por estudiar Letras y Bellas Artes.

«No me animo a bacer una carrera larga».

Se inscriben en esta última categoría algunos (sobre todo algunas) de los candidatos a carreras no universitarias, tales como Turismo, Relaciones Públicas y, especialmente, ATS. 


\subsection{Rasgos más característicos.}

En las páginas que anteceden hemos tratado de exponer con cierto detalle el peso específico de cada una de las distintas categorías de motivaciones percibidas por los estudiantes de COU como determinantes de su elección de carrera. Antes de finalizar quisiéramos ahora esbozar una síntesis de lo que podrían ser las principales conclusiones a que conducen los datos de que disponemos. Se tratatía, concretamente, de reunir las diferencias más significativas observadas entre chicos y chicas (las de los distintos centros de enseñanza que integran el universo han sido ya subrayadas), paza pasar posteriormente a una caracterización de las principales carreras según las motivaciones que con mayor frecuencia aparecen asociadas a ellas.

Las tazones que pot su mayor frecuencia más distinguen a las muchachas de sus compañeros vatones son las siguientes; autorrealización y servicio a los demás; relación con los demás, profesión humana y profesión interesante; la investigación; la adquisición de conocimientos y la enseñanza (incluyendo la variante de amor a los niños). En cambio, los motivos que aparecen como más característicos de los chicos son: las aptitudes, la vocación, el interés individual, el futuro de la profesión, sus salidas y las razones económicas; y, finalmente, las razones de tipo familiar. Se observará, pues, que entre las motivaciones «típicamente masculinas» aparecen todas las relacionadas con el futuro profesional del individuo, sus ambiciones, el situarse, y el ganarse bien la vida. Los chicos parecen asimismo más atentos a los condicionamientos a que están sujetos, ya sea por cuestiones familiares, ya en razón de sus propias aptitudes. Las muchachas se caracterizarían, en cambio, por un mayor altruísmo y por una mayor voluntad de hallar satísfacciones de tipo personal en la futura profesión, renunciando a una ambición de prestigio o de dineto en aras de un humanismo desinteresado, de la investigación, de la adquisición de conocimientos y de su transmisión a las nuevas generaciones.

En cuanto a las distintas carteras, veamos como quedan claramente delimitadas a partir de los distintos tipos de motivos percibidos como detetminantes:

- la vocación, la autorrealización, la entrega y el servicio a los demás se asocian netamente a los estudios de Medicina, Ma. gisterio $\mathrm{y}$, secundariamente, ATS.

- Ia adquisición de conocimientos, la enseñanza, y la despreocu- 
pación por las salidas económicas son las características de Magisterio, Letras, Psicología y Bellas Artes.

- la voluntad de dedicarse a la investigación motiva fundamentalmente a cursar las carreras de la Facultad de Ciencias.

- Ia preocupacion por las salidas, el futuro y las razones económicas inducen a escoger de preferencia los estudios de Ingeniero y Económicas y Empresatiales, y, secundariamente, Farmacia, Química y Medicina.

- finalmente, y según ya vimos, las razones de tipo familiar pesan sobre todo en quienes se inclinan por los estudios de Medicina, Economia, Derecbo, Ingeniería, Farmacia y Arquitectura, mien. tras que el argumento «me gusta» es común a todas las carre. ras $\sin$ excepción.

\subsection{La imagen ideal de la profesión.}

Las respuestas a la última pregunta de nuestra tncuesta, sobre la imagen ideal de la profesión elegida por los estudiantes de COU, no aporta grandes elementos nuevos a los datos ya conocidos y comentados sobre las motivaciones. En ciertas ocasiones proporcionan, no obstante, una información complementatia y útil para una mejor comprensión de estas mismas motivaciones. Agrupados por carreras, éstos son los principales resultados obtenidos.

\section{Medicina.}

¿Cuál es el perfil ideal del médico para los 153 alumnos de COU de nuestro universo que se destinan a esta cartera? El médico es para ellos, ante todo, una persona que debe estar constantemente dispuesta a ayudar a los demás, a darse incluso, y a curar al enfermo pero no limitándose sim. plemente a curarle, sino que simultáneamente debe luchar por la consecución de una mayor justicia sanitaria en el país, teniendo en cuenta la dimensión social de su actividad profesional. Finalmente, debe ser un hombre (o una mujer) menos preocupado por ganat dinero («no forrarse con el pretexto de sus poderes semi-mágicos»), y según algunos ha de poder dedicarse también a la investigación. 
ATS.

Dos son las finalidades básicas de esta profesión que se desprenden de las respuestas: ayudar a los enfermos por una parte y ayudar al médico por otra.

\section{Farmacia.}

La investigación debe constituir la razón de ser fundamental del profesional de esta carrera. Investigación puesta, siempre, por otra parte, al servicio de los demás.

\section{Veterinaria.}

Dos son las orientaciones básicas de esta carrera para aquellos que desean cursarla: la ayuda a los animales, y la lucha por el control y la mejora de la calidad de los alimentos que consumimos.

\section{Biológicas.}

El futuro biólogo se percibe fundamentalmente como un investigador (en 45 de los 54 casos con que contamos); pero prevé con frecuencia ya desde ahora serias dificuitades: la "calamitosa situación en que se halla actualmente la investigación en España».

\section{Quimica.}

También el químico debiera dedicarse principalmente a la investigación, proporcionando con sus descubrimientos medios para una mejora de la sociedad y de las condiciones de vida (en la lucha contra la contaminación, por ejemplo).

\section{Otras carreras de Ciencias.}

El físico debe investigar, el geólogo ha de estudiar el suelo, y el matetnático es aquel que se dedicará a la investigación y a la enseñanza. 
Ingeniero (e ingeniero técnico).

También el Ingeniero es percibido como un investigador, pero más aún como una persona que con sus conocimientos técnicos y su competencia contribuye al desarrollo del país, prestando de este modo una contribución a la sociedad entera. No obstante, en este caso son numerosas las respuestas en las que el individuo habla de sí mismo más que del rol del ingeniero en general, y se refiere entonces a su deseo de entrar en una empresa, conseguir un «trabajo importante», y ganarse holgadamente la vida. Precisemos todavía que este tipo de reacción se da sólo, además, en el caso de los futuros economistas y empresatios (y en algún caso, abogados).

\section{Arquitectura.}

La función del arquitecto consiste en trabajat por la comodidad y el bienestar de los demás, mediante unas construcciones adecuadas. En segundo lugar aparece en este perfil ideal la figura del urbanista, concebido como aquél que en vez de construir casas o edificios aislados, se dedica a la planificación de la ciudad en general.

Bellas Artes.

Constatamos en este caso una gran diversidas de imágenes: el decorador, el diseñador, y también el individuo que pretende trabajar con la máxima libettad y que busca en la expresión artística un medio de comunicación con los demás (este último punto es más jatente aun entre aquellos que desean estudiar Música).

Magisterio y Pedagogía.

Obviamente, la imagen del maestro es la de una persona que enseña, que forma, que educa. Pero muchos de los aspirantes a estos estudios aportan mayores precisiones: para ellos el maestro ideal es aquel que «educa para la libertad», «para formar a los hombres del mañana», y que sabe crear con sus alumnos una atmósfera de comprensión y de amistad.

Filosofía y Letras.

La enseñanza, la investigación, el afán de conocimientos y la política 
son los cuatro elementos principales que integtan la imagen que del filósofo, filólogo o historiador se forjan los aspirantes a esta carrera.

\section{Psicología.}

El conocimiento y la comprensión del otro, y la posibilidad de orientarle y ayudarle, conformarían según nuestros estudiantes el perfil del psicólogo ideal.

\section{Sociologia.}

El sociólogo ha de ser una persona que estudia los hechos sociales con el fin de mejorar la sociedad (versión moderada) o de transformarla (versión radical), haciendo tomar conciencia a los demás de los problemas y de sus causas.

\section{Económicas.}

Se definiría idealmente al economista como el individuo capaz de solventar los problemas económicos de una sociedad, y que lucha por una mayor justicia y un mejor reparto de los bienes. En muchos casos, sin embargo, las esperanzas del futuro economista se cifran en logtar la ditección (eficaz) de una empresa, teniendo bien presentes los aspectos crematísticos y de prestigio de la cuestión.

Empresariales.

La organización y dirección de empresas constituyen en este caso el objetivo en el que unánimemente coinciden cuantos piensan cuxsar estos estudios.

Derecbo.

En pocas profesiones se observa mayor disparidad (por no decir contradicción) de imágenes: predomina la de quienes ven en el jurista al hombre que debe defender la justicia y servir así a la sociedad, pero son igualmente numerosos los que aspiran a instalarse como abogados, o a establecer una gestoría.

\section{Periodismo.}

El petiodista es, en cambio, unánimemente percibido como aquel que 
debe dar de la realidad y de los acontecimientos una información veraz $y$ sincera.

Olros.

Mencionemos, por último, entre las restantes profesiones, al especia* lista en relaciones públicas, dedicado a la promoción de las relaciones humanas, y al de turismo, con el objetivo de promocionar este tipo de actividades.

\section{CONCLUSTON.}

En las distintas fases de este pequeño estudio sobre una muestra de 930 estudiantes del Curso de Orientacion Univetsitaria en Batcelona hemos pasado de una descripción de la población encuestada a un análisis de las carreras o tipos de estudios que van a cursar a jartir del año próximo, así como de los motivos por los que han elegido dichos estudios y de la imagen ideal que del profesional en que pretenden convertirse se forjan en la actuaIidad.

En el nivel más puramente sociográfico hemos comprobado que el estuciante de COU es normalmente un barcelonés, de edad comprendida entre los 16 y los 18 años, y de clase media o alta. Sólo los estudiantes del COU nocturno que forma parte del universo y, en menor medida, las del Instituto Nacional, se diferencian del resto de las escuelas tanto por la edad como por el origen geográfico $\mathrm{y}$, sobre todo, social. Los resultados a este respecto confirman una vez más el hecho hasta ahora inamovible de la desigualdad de los distintos grupos sociales frente a la educación.

Los datos referentes a la elección de carreras demuestran la persistencia del masivo interés de los últimos años por los estudios de Medicina, así como la pervivencia de una serie de carreras consideradas como típicamente femeninas" —n especial Magisterio, Farmacia, Letras y ATS- frente a otras eminentemente «masculinas» - Ingeniería, Económicas y Arquitectura en particular-; con todo, no es menos cierto que otros estudios antaño reservados casi exclusivamente a los vatones -Ciencias, la misma Medicina y Derecho- son escogidas en la actualidad por gran númeto de muchachas. El ensayo de prevision, limitado y de alcance sólo local, que aquí se hace podría revelarse útil si fuera realizado en gran escala y más a largo plazo, y permitiera la adopción de medidas eficaces para paliar lo que de otro modo inevitablemente se presenta como fuente de conflictos y de 
frustraciones para lograr el acceso a las ahoras estrechas puertas de la Univetsidad.

Un análisis de los casos de coincidencia entre la carrera elegida y la profesión del padre, $y$, más en general, de la relación existente entre la opción por unos estudios determinados y el status socio-económico de la familia del estudiante, pone de manifiesto el influjo de una serie de condicionamientos sociales sobre la supuestamente autónoma decisión y vocación del individuo. Este peso de los condicionamientos sociales se revela particularmente fuerte en el caso de los estudios de Derecho, Farmacia y Ciencias Económicas y Empresariales (asociadas a un status social elevado), y de Magisterio y secundariamente de otras carreras no estrictamente universitarias (vinculadas a un status social más bajo).

Sin embargo, estos condicionamientos son a menudo inconscientes o culturalmente "dados por supuestos», de tal modo que no aparecen entre las motivaciones explícitas y subjetivamente aducidas por los encuestados para justificar su opción en pro de unos estudios determinados. Entre tales motivaciones destacan, por su importancia numética, el simple y tajante: «porque me gusta», así como el juicio sobre las propias aptitudes, una serie de razones altruístas (de ayuda y servicio a los demás), la voluntad de adquisición y luego de transmisión de los conocimientos (en el caso de la enseñanza), y finalmente la preocupación por el futuro profesional y la situación económica a que los estudios pueden dar acceso, amén de un grupo particular de motivos que hemos denominado «razones de tipo familiar», ligadas a la coincidencia con la profesión o cargo del padre a que antes aludíamos.

Por último, este análisis de las distintas motivaciones se ve complementado por un breve examen de las imágenes o perfiles ideales que de cada una de las profesiones se desprenden según el juicio de quienes, a partir del próximo curso académico, pretenden cursar aquel determinado tipo de estudios.

Huelga decir que estas notas sobre el fenómeno de la elección de carrera y sus motivaciones, aunque extensas, son parciales e incompletas; en primer lugar, por el carácter local y limitado del universo que ha sido objeto del estudio, y en segundo lugar por cuanto un análisis más en profundidad del capítulo de las motivaciones requeriría obviamente un tratamiento plutidisciplinat. Con todo, y pese a sus limitaciones, consideramos que el material presentado ofrece un interés indudable, tanto por confirmax en algunos casos hechos ya conocidos, como por abrit quizás, en otros, posibles caminos para ulteriores investigaciones. 